\title{
ESTIMATED COSTS OF TREATMENT OF BENIGN PROSTATE HYPERPLASIA IN BRAZIL
}

\author{
HAYLTON J. SUAID, MARCO A. GONÇALVES, ANTONIO A. RODRIGUES JR, JOÃO P \\ CUNHA, ADAUTO J. COLOGNA, ANTONIO C.P. MARTINS \\ Division of Urology, Department of Surgery and Anatomy, Ribeirão Preto Medical \\ School, University of São Paulo, São Paulo, SP, Brazil
}

\begin{abstract}
Introduction: The treatment of benign prostate hyperplasia $(\mathrm{BPH})$ presents 2 options: medical or surgical, and there are doubts about what is the best treatment since $80 \%$ of patients who undergo surgery become asymptomatic and 10 to $40 \%$ of those under medical regimen undergo surgery within a 5 years period. It is difficult to assess the actual costs of treating BPH in Brazil due to several factors, among them regional particularities and the scarcity of current statistical data.

Patients and Methods: Recently, in the Ribeirão Preto area, São Paulo, Brazil, the IPSS (International Prostatic Symptoms Score) and quality of life were verified in 934 volunteers. It was determined the percentage of individuals with ages ranging from 40 to 79 years with moderate symptoms (score 8-19) and with severe symptoms (score 20-35), values for which are indicated medical and surgical treatment, respectively, according to the Brazilian Society of Urology consensus on BPH. Data on Brazilian population in that age range were obtained from the Brazilian Institute of Geography and Statistics referent to the year of 2000. It was determined the number of patients, according to the criteria above, subjected to either one of the treatments mentioned. Surgical costs of prostate transurethral resection were researched according to Unified Health System - SUS tables (US\$ 173) and of Brazilian Medical Society - AMB with a mean cost in 3 hospitals of US\$ 933. Drug costs were calculated by the annual mean price (US\$ 355) of 4 alpha-blockers (tamsulosin, alfuzosin, doxazosin and terazosin).

Results: The estimated population for medical treatment was 5,397,321 individuals, with a cost corresponding to US\$1,916,489,055.00. The estimated population for surgical treatment was 2,040,299 men, what would represent a cost of US\$353,291,204.00 based on the SUS table and of US\$1,904,279,066.00 based on AMB with hospital expenses included.

Conclusion: All theses facts induce us to predict that the treatment of BPH in a not-so-far future can become a public health problem for Brazilian society, since the current estimate would be, approximately, costs around $2.26-3.83$ billion dollars, added by the yearly increase in the risk population $(24.99 \%)$ for the group under medical treatment and over the non-operated amount of the surgical group.
\end{abstract}

Key words: prostate; prostatic hyperplasia; drug therapy; surgery; treatment costs Int Braz J Urol. 2003; 29: 234-237

\section{INTRODUCTION}

Benign prostate hyperplasia $(\mathrm{BPH})$ is very frequent in men and its prevalence increases with age, reaching figures of $85 \%$ to $90 \%$ in the age range above
80 years (1). The intensity lower urinary tract symptoms fluctuates with time and may no be consequent to BPH (2). This fact makes the identification of defined criteria difficult for indicating treatment, since about $80 \%$ of patients subjected to surgery become 
asymptomatic (3). Brazilian consensus tried to define some parameters for guidance when indicating any type of treatment for BPH based in IPSS score. Thus, observation was recommended for cases with scores lower than 8 . For patients with values between 8 and 19 pharmacological treatment would be indicated, and above these levels (20 to 35) the option would be surgical (4). In the United States of America, transurethral resection of the prostate (TURP) is the second most performed surgical procedure, with an estimated cost between 2 to 3 billion dollars per year. As for costs with pharmacological treatment during a 5-year period, it is expected to range between US\$ $1,800.00$ and US\$ 3,150.00 dollars/patient (5). The purpose of the present work was to estimate, with data from the Brazilian population, which would be the cost of BPH treatment.

\section{MATERIALS AND METHODS}

In 1997 it was made a screening for early diagnosis of prostate cancer, where 1,106 volunteers were examined. The IPSS and quality of life were verified in all patients. To assess the participation of patients only with $\mathrm{BPH}$, patients presenting cancer, intraepithelial neoplasia or those who refused biopsies when indicated were excluded, with 934 volunteers remaining for study. The results from this assessment allowed the creation of a table referent to frequency and distribution of lower urinary tract symptoms and signs in age ranges between 40 years and 79 years (Table-1), as well as score classification according to what was determined by the National consensus on BPH (6) (Table-2). The number of men pertaining to each age range existing in Brazil was obtained from the national census of 2000 , conducted by the Brazilian Institute of Geography and Statistics (IBGE) (7) (Table-3). Having the frequency percentages of IPSS in several ranges of population under study, the total of risk population in each range and the criteria for indicating the type of treatment, the estimated number of individuals subjected to pharmacological and surgical treatments was obtained. The mean annual cost (September/2002) of drug treat-

Table 1 - Frequency of lower urinary tract symptoms according to age range in years.

\begin{tabular}{|c|c|c|c|c|c|c|c|c|c|c|c|c|c|c|}
\hline \multirow{2}{*}{$\begin{array}{l}\text { Age } \\
\text { Range }\end{array}$} & \multicolumn{2}{|c|}{ IVE } & \multicolumn{2}{|c|}{$\mathbf{P}$} & \multicolumn{2}{|c|}{$\mathbf{H}$} & \multicolumn{2}{|c|}{$\mathbf{U}$} & \multicolumn{2}{|c|}{ WFR } & \multicolumn{2}{|c|}{ VE } & \multicolumn{2}{|c|}{$\mathbf{N}$} \\
\hline & f & $\%$ & f & $\%$ & f & $\%$ & f & $\%$ & $\mathbf{f}$ & $\%$ & f & $\%$ & f & $\%$ \\
\hline $40-49$ & 72 & 28.1 & 107 & 41.8 & 62 & 24.2 & 46 & 14.1 & 85 & 33.2 & 57 & 22.3 & 159 & 62.1 \\
\hline $50-59$ & 99 & 28.9 & 152 & 44.3 & 103 & 30.0 & 57 & 16.6 & 118 & 34.4 & 78 & 22.7 & 244 & 71.1 \\
\hline $60-69$ & 101 & 39.1 & 132 & 52.2 & 98 & 38.7 & 80 & 31.6 & 137 & 54.2 & 71 & 28.1 & 200 & 79.1 \\
\hline $70-79$ & 38 & 46.3 & 44 & 53.7 & 37 & 45.1 & 41 & 50.0 & 79 & 59.8 & 29 & 35.4 & 73 & 89.0 \\
\hline
\end{tabular}

IVV-feeling of incomplete vesical emptying; $P$ - pollakiuria; $H$ - hesitation; $U$-voiding urgency; WFR - weak flow rate; VE-voiding effort; $N$ - nycturia; $f$-frequency.

Table 2 - Intensity of lower urinary tract symptoms score according to age range in years.

\begin{tabular}{lcccccc}
\hline \multirow{2}{*}{$\begin{array}{l}\text { Age } \\
\text { Range }\end{array}$} & \multicolumn{2}{c}{ Score 0 - 7 } & \multicolumn{2}{c}{ Score 8 - 19 } & \multicolumn{2}{c}{ Score 20 - 35 } \\
f & $\mathbf{~ \% ~}$ & f & \% & f & \% \\
\hline $40-49$ & 182 & 71.0 & 53 & 20.7 & 21 & 8.3 \\
$50-59$ & 233 & 67.9 & 81 & 23.6 & 29 & 8.5 \\
$60-69$ & 131 & 57.1 & 86 & 34.0 & 36 & 8.9 \\
$70-79$ & 34 & 41.4 & 31 & 37.8 & 17 & 20.8 \\
\hline
\end{tabular}

$f$-frequency. 
Table 3 - Population of Brazilian men, divided by age range in years.

\begin{tabular}{lc}
\hline Age Range & Number of Men \\
$40-49$ & $9,332,857$ \\
$50-59$ & $6,000,922$ \\
$60-69$ & $3,792,534$ \\
$70-79$ & $2,009,900$ \\
Total & $21,136,213$ \\
\hline
\end{tabular}

ment, based on prices of alpha-blockers (tamsulosin, alfuzosin, doxazosin and terazosin) in minimal dosages prescribed, was calculated in US\$ 355 per patient. The surgical cost of TURP as per SUS table was budgeted in US\$173 per patient and as per AMB table in US\$ 933 per patient including hospital expenses.

From this data, the costs of drug and surgical treatments were calculated for each age range, thus obtaining the estimated total value (Table-6).

\section{RESULTS}

Population subjected to medical treatment with IPSS of 8 to 19 , according to the age range is presented in Table-4. The value obtained for medical treatment of the estimated risk population, was determined from calculation: 5,397,321 (patients) x US\$ $355.00=$ US\$ 1,916,489,055.00.

As for surgical treatment the estimated risk population is presented in Table-5. The value obtained for surgical treatment of estimated risk population, based on the SUS table, was determined from calculation: 2,040,299 (patients) x US\$ $173.00=$ US\$ $353,291,204.00$. Estimated cost for surgical treatment based on AMB table's values was obtained from calculation: $2,040,299 \times$ US\$ $933.00=$ US\$ $1,904,279,066.00$.

Total values found for treatment of BPH in Brazil are presented in Table- 6 and represent the sum of medical and surgical treatments.

Table 4 - Estimated risk population subjected to medical treatment, according to age range in years.

\begin{tabular}{lccc}
\hline Age Range & Detected Population & Risk Percentage & Estimated Population \\
\hline $40-49$ & $9,332,857$ & $20.7 \%$ & $1,931,901$ \\
$50-59$ & $6,000,922$ & $23.6 \%$ & $1,416,217$ \\
$60-69$ & $3,792,534$ & $34.0 \%$ & $1,289,461$ \\
$70-79$ & $2,099,900$ & $37.8 \%$ & 759,742 \\
Total & & & $5,397,321$ \\
\hline
\end{tabular}

Table 5 - Estimated risk population subjected to surgical treatment, according to age range in years.

\begin{tabular}{lccc}
\hline Age Range & Detected Population & Risk Percentage & Estimated Population \\
\hline $40-49$ & $9,332,857$ & $8.3 \%$ & 774,627 \\
$50-59$ & $6,000,922$ & $8.5 \%$ & 510,078 \\
$60-69$ & $3,792,534$ & $8.9 \%$ & 337,535 \\
$70-79$ & $2,099,900$ & $20.8 \%$ & 418,059 \\
Total & & & $2,040,299$ \\
\hline
\end{tabular}

Table 6 - Total annual estimate costs needed for treatment of BPH in Brazil in 2002.

\begin{tabular}{lcc}
\hline Medical Treatment & Surgical Treatment (SUS) & Surgical Treatment (AMB) \\
\hline US\$ $1,916,489,055.00$ & US $\$ 353,291,204.00$ & US $\$ 1,904,279,066.00$ \\
\hline
\end{tabular}

SUS - Unified Health System; AMB - Brazilian Medical Association 


\section{DISCUSSION}

In 1999 it was presented a work concerning the estimated costs of BPH treatment in Brazil. At the time, the estimated population for calculation was obtained through IBGE data from 1996. We were impressed by the values determined, especially in reference to costs of medical treatment. Four years later we decided to reassess those numbers to get an idea about their evolution. There was a significant increase in risk population both for medical treatment $(52.4 \%)$ and for surgical treatment $(118.7 \%)$. Such data show that Brazilian population is growing older, with a significant increase in risk population for $\mathrm{BPH}$ treatment. Associated with the population growth is the increase in the procedure costs. Drugs cost has raised about $21.02 \%$. SUS added about $69.19 \%$ to TURP package, noting the addition of anesthetist's medical fees, which were separated from the package. AMB table plus hospital expenses suffered an increase of $26.6 \%$ for TURP. The sum of these factors has promoted an increased in the costs of annual medical treatment for the risk population total of US\$ $877,292,155.00$, that is, $84.5 \%$. On the other hand, annual SUS cost to finance surgical treatment of risk population has increased about US\$258,360,324.00, which means an addition of $270.2 \%$. As for TURP costs according to AMB table for medical fees plus hospital costs, it was calculated an addition of US\$ $1,216,702,071.00$, which represents an increase of $176.9 \%$.

This work's intention is not discuss if such increases could represent substantial gains to urologists or not, but to analyze the necessary amount to be spent by the community in order to finance BPH treatment. Obviously, these costs can present variations with time due to the annual percentage increase in risk population, which were calculated in $24.99 \%$ for both groups. For the medical group this percentage is added yearly. However for the surgical group this percentage falls over the non-operated amount.

Another interesting fact is that the total resources spent with medical treatment are really significant, showing that the urologist must be moderate in his/her indications so that he/she will not burden society too much.
All theses facts induce us to foresee that the treatment of BPH in a not-so-far future can become a public health problem for Brazilian society, since the current estimate would be of costs around 2.26 to 3.83 billion dollars, added by the yearly increase in the risk population (24.99\%) for the group under medical treatment and over the non-operated amount of the surgical group.

\section{REFERENCES}

1. Claus GR, John DM: Etiology, Pathophysiology, Epidemiology and Natural History of Benign Prostatic Hyperplasia - In: Walsh PC (ed.), Campbell's Urology. Philadelphia, Saunders. 2002; pp. 1297-1336.

2. Bosch JLHR, Hop WCJ, Kirkels WJ, Schroeder FH: The International Prostatic Symptoms in a communitybased sample of men between 55 and 74 years of age: prevalence and correlation of symptoms with age, prostate volume, flow rate and residual volume. Br J Urol. 1995; 75: 622-30.

3. Malone PR, Cook A, Admonson R, Gill MW, Shearer RJ: Prostatectomy: patients' perception and long-term follow-up. Br J Urol. 1988; 61: 234-8.

4. Rodrigues Netto Jr. N, Zerati Filho M, Ikari O: Treatment of BPH. Criteria for Medical or Surgical Treatment. In: Toledo WP: I Meeting of National Consensus in BPH. Brazilian Society of Urology. BG Cultural, São Paulo. 1996; pp. 65 [in Portuguese].

5. Uro News - Internet - Brazilian Society of Information in Urological Pathology. 1996; 5:7 [in Portuguese].

6. Martins ACP, Falconi RAR, Suaid HJ, Cologna AJ, Reis AJ, Cortez RR: Benign prostatic hyperplasia (BPH). Some epidemiological data in Ribeirão Preto. Rev Col Bras Cir. 1999; 26 (supl 1): 21 [in Portuguese].

7. ibge.gov.br/ - população - censo demográfico 2000 resultados do universo.

Received: October 24, 2002

Accepted after revision: April 11, 2003 